\title{
Accuracy of self-reported height, weight, and waist circumference in a general adult Chinese population
}

\author{
Shurong Lu, Jian Su, Quanyong Xiang, Jinyi Zhou and Ming Wu*
}

\begin{abstract}
Background: Self-reported height, weight, and waist circumference (WC) are widely used to estimate the prevalence of obesity, which has been increasing rapidly in China, but there is limited evidence for the accuracy of self-reported data and the determinants of self-report bias among the general adult Chinese population.

Methods: Using a multi-stage cluster sampling method, 8399 residents aged 18 or above were interviewed in the Jiangsu Province of China. Information on self-reported height, weight, and WC, together with information on demographic factors and lifestyle behaviors, were collected through structured face-to-face interviews. Anthropometrics were measured by trained staff according to a standard protocol.

Results: Self-reported height was overreported by a mean of $1.1 \mathrm{~cm}$ (95\% confidence interval [CI]: 1.0 to 1.2). Self-reported weight, body mass index (BMI), and WC were underreported by $-0.1 \mathrm{~kg}$ (95\% Cl: -0.2 to 0.0 ), $-0.4 \mathrm{~kg} / \mathrm{m}^{2}$ (95\% Cl: -0.5 to -0.3 ) and $-1.5 \mathrm{~cm}$ (95\% Cl: -1.7 to -1.3 ) respectively. Sex, age group, location, education, weight status, fruit/vegetable intake, and smoking significantly affected the extent of self-report bias. According to the self-reported data, $25.5 \%$ of obese people were misclassified into lower BMI categories and $8.7 \%$ of people with elevated WC were misclassified as normal. Besides the accuracy, the distribution of BMI and WC and their cut-off point standards for obesity of a population affected the proportion of obesity misclassification.

Conclusion: Amongst a general population of Chinese adults, there was rather high proportion of obesity misclassification using self-reported weight, height, and WC data. Self-reported anthropometrics are biased and misleading. Objective measurements are recommended.
\end{abstract}

Keywords: Accuracy, Adults, Body height, Body mass index (BMI), Body weight, Obesity, Waist circumference (WC)

\section{Background}

As the most commonly used measure of obesity in adults, body mass index $\left(\mathrm{BMI}, \mathrm{kg} / \mathrm{m}^{2}\right)$ is calculated as weight $(\mathrm{kg})$ divided by squared height (meters). Knowledge on the weight and height of a population enables subgroups to be identified that are at increased risk of developing obesity-related health problems and dying prematurely [1,2]. As self-reported height and weight are easier, cheaper, and quicker to collect compared with direct measurements [3], they have been widely used in disease surveillance, web-based studies, telephone interviews, and other types of research $[4,5]$. Previous studies

\footnotetext{
* Correspondence: jswuming@vip.sina.com

Department of Chronic Disease, Jiangsu Provincial Center for Disease Control and Prevention, 172, Jiangsu Road, 210009 Nanjing, China
}

suggest that, although self-reported data on height and weight were positively correlated with measured data [5], adults tend to overreport height and underreport weight, especially women, elderly people, or those with higher weight [6-8]. Inaccuracies in self-reported height and weight lead to biased calculations of BMI, and consequently to inaccurate assessment of the disease and mortality risk of a population $[2,6,9]$.

While BMI is a measure of overall obesity, waist circumference (WC) is an internationally used measure of abdominal obesity [1]. In the limited number of studies that have been performed on the accuracy of selfreported WC in adults, underreporting of WC has been the most consistent finding $[2,8,10]$. Very few studies assessed the accuracy of self-reported WC as well as that 
of self-reported weight, height, and BMI in the same population $[2,10]$.

Some studies have investigated the association between the accuracy of self-report bias and certain sociodemographic characteristics besides sex, age, and BMI status $[2,7,9,11]$, such as socioeconomic status $[2,11]$ and ethnicity $[7,9,11]$. Low socioeconomic status was consistently related to greater self-report bias, but evidence for ethnicity is inconsistent. A limited number of studies examined the effect of certain lifestyle factors on the accuracy of self-reported anthropometrics. For example, smoking $[2,12]$ was found to be significantly related to reduced bias. Studies suggested that diet may be another behavioral factor associated with the accuracy of self-reported data [10]. However, no association between the accuracy of self-reported anthropometrics and alcohol consumption or physical activity level has been identified, despite both being important behavioral risk factors for obesity.

Instead of targeting a general population, most studies on accuracy or validity of self-reported data focused on subgroup populations, such as overweight population, middleaged adults, or college students $[2,5,8,10]$. The limited number of studies performed at a general population level, mostly in Western countries [13, 14], have revealed substantial differences in self-reported anthropometrics bias between populations of different countries [13]. The accuracy and determinants of bias in self-reported anthropometrics of general adults of China have not been studied yet. China differs from Western countries both in the epidemical characteristics of obesity and in social desirability toward obesity. On the one hand, even with a substantial increase from $7.1 \%$ in 2002 to $12.0 \%$ in $2010[15,16]$, the prevalence of obesity is still relatively low compared to that of Western countries. On the other hand, because of earlier experiences with long-term poverty and famine, the Chinese traditionally believe that being overweight is a sign of happiness and abundance rather than a health problem [17]. Therefore, we believe that this countryspecific study, which aimed to examine the accuracy of self-reported height, weight, and WC, is needed and will enrich the literature of self-reported anthropometrics in non-Western countries.

\section{Methods}

\section{Setting and participants}

The data presented in this article are from the 2013 Jiangsu Provincial Surveillance Survey on Chronic Disease and Behavioral Risk Factors, a community-based cross-sectional survey, ethically approved by the Institutional Review Board of the Jiangsu Provincial Department of Health. Jiangsu Province lies in the southeast of China, with a population of 79.6 million. There are 13 cities in Jiangsu that comprise 98 counties/districts (representing rural areas and urban areas, respectively, according to the Chinese administrative division criteria), of which 14 are provincial disease surveillance points (DSPs). These 14 DSPs are representative of Jiangsu province in terms of geographical distribution, economic development, and population composition [18].

A multi-stage cluster sampling method was employed to select participants. Firstly, four towns/streets were selected from each DSP by proportion to population size sampling method [19]. Secondly, three villages/communities were selected from each selected town/street. Within each selected village/community, 50 households (private dwellings) were randomly sampled. By the Kish Grid method [20], one eligible resident (aged 18 or more, residing in the household for a minimum of six months prior to the survey) was selected to participate in the survey from all eligible people within each household. The target sample size was 600 respondents per DSP and 8400 (600/DSP*14DSPs) for the total.

\section{Procedure}

Local village/community general practitioners invited the selected residents to participate in the study and informed them of the specific location and time. All participants gave written informed consent upon arriving at the survey site, which were primarily village/community health service stations.

Each participant completed a face-to-face structured interview performed by a trained public health worker. The survey inquired about demographic characteristics and lifestyle factors (including smoking, alcohol drinking, diet, and physical activity), and asked Do you know your current height/weight/WC?. If participants reported knowing their current height, weight, and/or WC, they were asked to give the specific values (referred to as "selfreported data" in this analysis). "Current daily smoking" was defined as smoking at least once a day and "drinking alcohol within 30 days" was defined as having any alcoholic drink within the past 30 days. Information on the intake of meat and fruits/vegetables were collected by food frequency questionnaire. Furthermore, physical activity level was categorized according to the Global Physical Activity Questionnaire Analysis Guide of the World Health Organization [21]. Details of the interview and the methods for categorizing lifestyle factors have been described elsewhere [22].

Direct measurements of height, weight, and WC were taken by a team with two trained staff. The reliability and validity of the measurements of each team were tested in a standardized method by a local supervisor during staff training [22]. According to a standard protocol, height was measured to the nearest $0.1 \mathrm{~cm}$ without shoes using a stadiometer, weight was measured without shoes and excess clothing to the nearest $0.1 \mathrm{~kg}$ using digital scales, and 
WC was measured halfway between the inferior margin of the last rib and the iliac crest in the mid-axillary plane to the nearest $0.1 \mathrm{~cm}$ with a waist circumference measuring tape. For WC, if the variation between the first and second measurements was greater than $2 \mathrm{~cm}$, a third measurement was taken and the mean of the two closest measurements was calculated. These data are referred to as directly measured (DM) for the purpose of this study. All anthropometric measurements were completed in the morning. For weight and WC measurements, eight to $10 \mathrm{~h}$ of fasting was required.

\section{Statistical analysis}

BMI was calculated based on self-reported and measured height and weight. The BMI categories were identified using Chinese cut-off points as underweight $\left(<18.5 \mathrm{~kg} / \mathrm{m}^{2}\right)$, normal $\left(18.5-23.9 \mathrm{~kg} / \mathrm{m}^{2}\right)$, overweight $\left(24.0-27.9 \mathrm{~kg} / \mathrm{m}^{2}\right)$, and obese $\left(\geq 28.0 \mathrm{~kg} / \mathrm{m}^{2}\right)$ [23] , and using the World Health Organization standard as underweight $\left(<18.5 \mathrm{~kg} / \mathrm{m}^{2}\right)$, normal $\left(18.5-24.9 \mathrm{~kg} / \mathrm{m}^{2}\right)$, overweight $\left(25.0-29.9 \mathrm{~kg} / \mathrm{m}^{2}\right)$, and obese $\left(\geq 30.0 \mathrm{~kg} / \mathrm{m}^{2}\right)[1]$. WC was grouped into "elevated" (men $\geq 90 \mathrm{~cm} /$ women $\geq 80 \mathrm{~cm}$ or men $\geq 102 \mathrm{~cm} /$ women $\geq 88 \mathrm{~cm})$ and "normal" (men $<90 \mathrm{~cm} /$ women $<80 \mathrm{~cm}$ or men $<102 \mathrm{~cm} /$ women $<88 \mathrm{~cm}$ ) according to the International Diabetes Federation standard for the Chinese or for the Americans [24]. Reliability between self-reported and measured values of continuous variables was evaluated with the use of intraclass correlation and $95 \%$ confidence intervals. BlandAltman plots were used in order to examine the individual agreement between self-reported and measured anthropometrics [25]. Group comparisons were performed using analysis of variance or $\chi^{2}$ tests as appropriate. Blocks of variables (sociodemographic factors, weight status, and lifestyle behaviors) were entered into the hierarchical regression models to allow analysis of their contributions to self-report bias after controlling for previously entered variables.

Data management and statistical analyses were performed using SPSS (V22.0, Chicago, Illinois) and $P<0.05$ (two sided) was considered to be significant.

\section{Results}

As shown in Fig. 1, there was a total of 8399 residents from the sample of 8400 who were interviewed, aged 18.0 to 93.7 years (average, $52.2 \pm 14.7$ years), and almost half were males (49.6\%). Participants with self-reported and measured height, weight, and WC were included in the analyses.

The intraclass correlation coefficients between selfreported and measured was 0.957 (95\% CI: 0.955, 0.960) for height, 0.959 (95 \% CI: 0.957, 0.961) for weight, 0.924 (95 \% CI: 0.920, 0.928) for BMI, and 0.918 (95\% CI: 0.912, 0.923) for WC, respectively, which demonstrated very high concordance between self-reported and measured data.

Descriptive statistics on the difference between selfreported and measured height, weight, BMI, and WC by sociodemographic characteristics were shown in Table 1. The mean difference (self-reported minus measured) was $1.1 \mathrm{~cm}(95 \% \mathrm{CI}: 1.0,1.2)$ for height, $-0.1 \mathrm{~kg}(95 \% \mathrm{CI}$ : $-0.2,0.0)$ for weight, $-0.4 \mathrm{~kg} / \mathrm{m}^{2}$ (95\% CI: $\left.-0.5,-0.3\right)$ for BMI, and $-1.5 \mathrm{~cm}(95 \% \mathrm{CI}:-1.7,-1.3)$ for WC, respectively. Compared with men, women showed much greater error in self-reported WC $(-1.9$ vs. $-0.9, P<0.001)$. The difference between self-reported and measured height increased significantly with increasing age $(P<0.001)$. The difference between self-reported and measured weight, $\mathrm{BMI}$, and WC were statistically significant among age groups as well, all $P<0.05$. Geographical location and level of education were related to a significant difference between self-reported and directly measured weight and

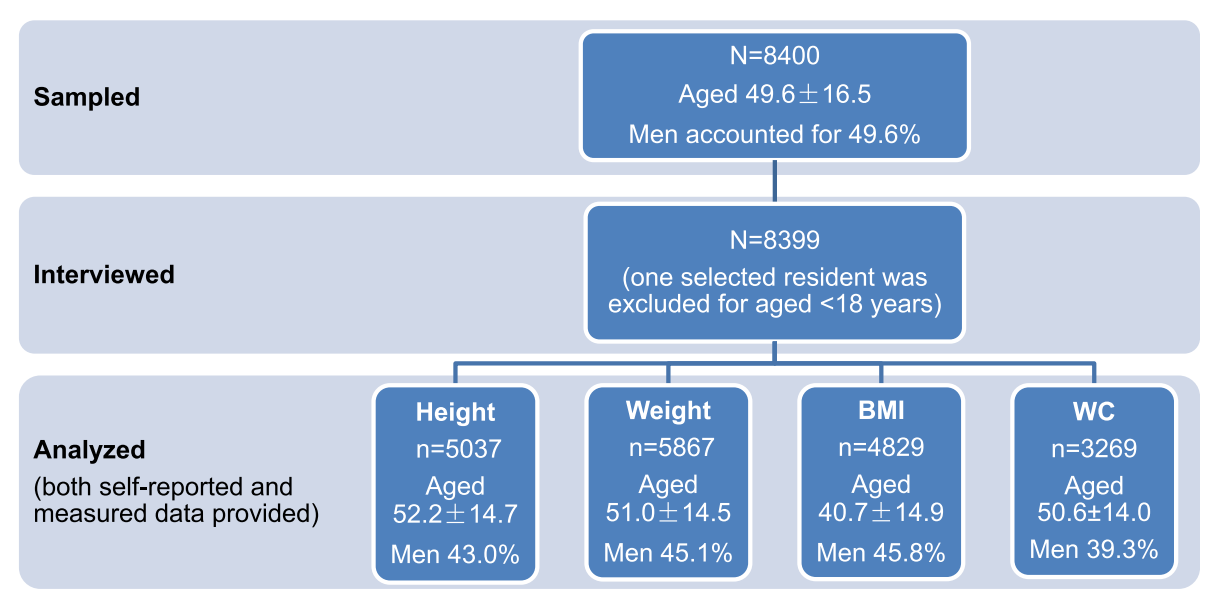

Fig. 1 Response rate and sample size of analysis. BMI: body mass index; WC: waist circumference 
Table 1 The difference between self-reported and measured (SR-DM) height, weight, BMI, and WC by sociodemographic factors in Jiangsu, China

\begin{tabular}{|c|c|c|c|c|c|c|c|c|c|c|c|c|c|}
\hline & & \multicolumn{3}{|c|}{ Height (cm) } & \multicolumn{3}{|c|}{ Weight (kg) } & \multicolumn{3}{|c|}{ BMI $\left(\mathrm{kg} / \mathrm{m}^{2}\right)$} & \multicolumn{3}{|c|}{ WC (cm) } \\
\hline & & $\mathrm{n}$ & Mean & $95 \% \mathrm{Cl}$ & $n$ & Mean & $95 \% \mathrm{Cl}$ & $n$ & Mean & $95 \% \mathrm{Cl}$ & $n$ & Mean & $95 \% \mathrm{Cl}$ \\
\hline \multicolumn{2}{|l|}{ Total } & 5037 & 1.1 & $1 \cdot 0,1 \cdot 2$ & 5867 & -0.1 & $-0.2,0.0$ & 4829 & -0.4 & $-0.5,-0.3$ & 3269 & -1.5 & $-1.7,-1.3$ \\
\hline \multirow[t]{3}{*}{ Sex } & Men & 2377 & 1.1 & $0.9,1.2$ & 2645 & -0.1 & $-0.2,0.1$ & 2278 & -0.4 & $-0.4,-0.3$ & 1285 & -0.9 & $-1.2,-0.5$ \\
\hline & Women & 2660 & 1.2 & $1.1,1.3$ & 3222 & -0.1 & $-0.2,0.1$ & 2551 & -0.4 & $-0.5,-0.4$ & 1984 & -1.9 & $-2.1,-1.7$ \\
\hline & $P$ value & 0.098 & & & 0.882 & & & 0.13 & & & $<0.001$ & & \\
\hline \multirow[t]{7}{*}{ Age group (years) } & $18-29$ & 569 & 0.5 & $0.4,0.7$ & 594 & -0.4 & $-0.8,0.1$ & 534 & -0.3 & $-0.5,-0.1$ & 292 & -1.2 & $-1.8,-0.6$ \\
\hline & $30-39$ & 661 & 0.7 & $0.5,0.9$ & 704 & -0.6 & $-0.8,-0.3$ & 637 & -0.4 & $-0.5,-0.3$ & 426 & -1.9 & $-2.4,-1.5$ \\
\hline & $40-49$ & 1221 & 0.9 & $0.8,1.0$ & 1389 & -0.1 & $-0.3,0.2$ & 1169 & -0.3 & $-0.4,-0.2$ & 837 & -1.9 & $-2.3,-1.5$ \\
\hline & $50-59$ & 1271 & 1.2 & $0.9,1.4$ & 1512 & 0.0 & $-0.2,0.1$ & 1224 & -0.4 & $-0.5,-0.3$ & 851 & -1.2 & $-1.5,-0.9$ \\
\hline & $60-69$ & 893 & 1.6 & $1.4,1.8$ & 1134 & 0.2 & $0.0,0.4$ & 863 & -0.5 & $-0.5,-0.4$ & 598 & -1.4 & $-1.9,-0.9$ \\
\hline & $70 \sim$ & 422 & 2.3 & $1.9,2.7$ & 534 & 0.3 & $-0.2,0.7$ & 402 & -0.6 & $-0.9,-0.4$ & 265 & -1.0 & $-1.6,-0.3$ \\
\hline & $P$ value & $<0.00$ & & & 0.002 & & & 0.025 & & & 0.015 & & \\
\hline \multirow[t]{3}{*}{ Locations } & Urban & 3982 & 1.2 & $1.1,1.3$ & 4223 & -0.2 & $-0.3,-0.1$ & 3875 & -0.4 & $-0.5,-0.4$ & 2592 & -1.3 & $-1.5,-1.1$ \\
\hline & Rural & 1055 & 1.0 & $0.8,1.2$ & 1644 & 0.3 & $0.0,0.5$ & 954 & -0.2 & $-0.4,-0.1$ & 677 & -2.2 & $-2.7,-1.7$ \\
\hline & $P$ value & 0.078 & & & $<0.00$ & & & 0.003 & & & 0.001 & & \\
\hline \multirow[t]{4}{*}{ Education } & Primary & 1495 & 1.4 & $1.2,1.7$ & 2107 & 0.2 & $0.0,0.4$ & 1392 & -0.4 & $-0.5,-0.4$ & 1027 & -1.7 & $-2.1,-1.4$ \\
\hline & Secondary & 2994 & 1.1 & $1.0,1.2$ & 3218 & -0.1 & $-0.3,0.0$ & 2902 & -0.4 & $-0.5,-0.3$ & 1927 & -1.5 & $-1.7,-1.2$ \\
\hline & University & 548 & 0.6 & $0.4,0.8$ & 542 & -0.7 & $-1.0,-0.4$ & 535 & -0.4 & $-0.5,-0.3$ & 315 & -0.9 & $-1.4,-0.4$ \\
\hline & $P$ value & 0.347 & & & $<0.00$ & & & 0.545 & & & 0.037 & & \\
\hline \multirow[t]{4}{*}{ Household income level } & Low & 1034 & 1.3 & $1.1,1.4$ & 1392 & 0.3 & $0.0,0.6$ & 962 & -0.3 & $-0.5,-0.2$ & 652 & -1.6 & $-2.0,-1.1$ \\
\hline & Moderate & 2550 & 1.1 & $0.9,1.2$ & 2911 & -0.1 & $-0.3,0.0$ & 2450 & -0.4 & $-0.5,-0.3$ & 1633 & -1.6 & $-1.9,-1.4$ \\
\hline & High & 1453 & 1.1 & $1 \cdot 0,1 \cdot 3$ & 1564 & -0.3 & $-0.4,-0.1$ & 1417 & -0.4 & $-0.5,-0.4$ & 984 & -1.2 & $-1.5,-0.9$ \\
\hline & $P$ value & 0.319 & & & 0.002 & & & 0.338 & & & 0.125 & & \\
\hline
\end{tabular}

Abbreviations: $B M I$ body mass index, $W C$ waist circumference, $C I$ confidence interval, $S R$ self-reported, $D M$ directly measured

WC, and household income level was significantly related to that of weight, all $P<0.05$.

Overweight or obese respondents were more likely to overestimate their height and underestimate their weight, BMI, and WC compared to normal and underweight respondents $(P<0.001)$, as did participants with elevated WC compared with those with normal WC, all $P<0.001$ (Table 2).

Respondents who were not daily smokers, had intakes of fruits/vegetables $\geq 400 \mathrm{~g} / \mathrm{d}$, or those with sufficient physical activity level were more likely to overreport their height $(P<0.001)$. Similarly, respondents who were

Table 2 The difference between self-reported and measured (SR-DM) height, weight, BMI, and WC by BMI categories and WC categories in Jiangsu, China

\begin{tabular}{|c|c|c|c|c|c|c|c|c|c|c|c|c|c|}
\hline & & \multicolumn{3}{|c|}{ Height $(\mathrm{cm})$} & \multicolumn{3}{|c|}{ Weight (kg) } & \multicolumn{3}{|c|}{ BMI $\left(\mathrm{kg} / \mathrm{m}^{2}\right)$} & \multicolumn{3}{|c|}{ WC (cm) } \\
\hline & & $n$ & Mean & $95 \% \mathrm{Cl}$ & $n$ & Mean & $95 \% \mathrm{Cl}$ & $n$ & Mean & $95 \% \mathrm{Cl}$ & $n$ & Mean & $95 \% \mathrm{Cl}$ \\
\hline \multirow[t]{5}{*}{ Measured BMI categories } & Underweight & 128 & 0.4 & $-0.1,0.9$ & 137 & 2.0 & $0.8,3.2$ & 118 & 0.5 & $-0.1,1.0$ & 72 & 1.0 & $0.2,1.8$ \\
\hline & Normal & 2247 & 0.9 & $0.8,1.0$ & 2536 & 0.4 & $0.2,0.6$ & 2156 & -0.1 & $-0.2,0.0$ & 1380 & -0.8 & $-1.0,-0.5$ \\
\hline & Overweight & 1931 & 1.2 & $1.1,1.4$ & 2301 & -0.2 & $-0.4,0.0$ & 1860 & -0.5 & $-0.6,-0.4$ & 1292 & -2.0 & $-2.3,-1.7$ \\
\hline & Obesity & 731 & 1.7 & $1.3,2.1$ & 893 & -1.3 & $-1.6,-1.0$ & 695 & -1.2 & $-1.4,-1.0$ & 525 & -2.6 & $-3.1,-2.1$ \\
\hline & $P$ value & \multicolumn{3}{|c|}{$<0.001$} & \multicolumn{3}{|c|}{$<0.001$} & \multicolumn{3}{|c|}{$<0.001$} & \multicolumn{3}{|c|}{$<0.001$} \\
\hline \multirow[t]{3}{*}{ Measured WC } & Normal & 3306 & 1.1 & $0.9,1.3$ & 3771 & 0.3 & $0.1,0.5$ & 2615 & -0.2 & $-0.3,-0.1$ & 2084 & -0.2 & $-0.4,-0.0$ \\
\hline & Elevated & 1731 & 1.2 & $1.0,1.4$ & 2095 & -0.4 & $-0.6,-0.2$ & 2214 & -0.6 & $-0.7,-0.5$ & 1185 & -2.8 & $-3.0,-2.6$ \\
\hline & $P$ value & \multicolumn{3}{|l|}{0.137} & \multicolumn{3}{|c|}{$<0.001$} & \multicolumn{3}{|c|}{$<0.001$} & \multicolumn{3}{|c|}{$<0.001$} \\
\hline
\end{tabular}


not daily smokers, not alcohol-drinking, had less meat intakes or more fruit/vegetable intakes were more likely to underreport their WC, all $P<0.05$. Behavioral factors were not significantly associated with the extent of bias of self-reported weight or BMI, except that smoking was associated with greater accuracy of self-reported height and weight $(P<0.001)$ and meat intake $\geq 100 \mathrm{~g} / \mathrm{d}$ with under estimation of weight $(P=0.033)$ (Table 3$)$.

The majority of differing values between self-reported and measured data fell within the limits of agreement, indicating a fairly good level of agreement between selfreported and measured data (Fig. 2). Bland-Altman plots demonstrated an approximately normal distribution of error in self-reported height but an uneven distribution of error in self-reported weight, BMI, and WC. The plots indicated that higher values of average weight ((self-reported + measured) $/ 2$ ) were related to a greater variance of bias in weight. Participants with BMI around $25 \mathrm{~kg} / \mathrm{m}^{2}$ or with WC between $80 \mathrm{~cm}$ and $100 \mathrm{~cm}$ had much greater variance in the bias of self-reported BMI or WC.

Of respondents whose directly measured height and weight values categorized them as obese according to the Chinese standard, $25.5 \%$ were misclassified (i.e., classified as overweight or normal weight) based on self-reported height and weight. A greater proportion of misclassification of weight status was observed among women than among men (35.8 \% vs. $11.6 \%)$. Based on self-reported WC, $16.3 \%$ of women and $2.6 \%$ of men ( $8.7 \%$ in all) with elevated WC (according to the IDF standard for Chinese) on direct measurement were misclassified as normal. Such proportions decreased to $21.0 \%$ in the obesity misclassification and conversely increased to $10.6 \%$ in the elevated WC when categorizing by the World Health Organization standard and the IDF standard for Americans, respectively (Table 4).

The results of hierarchical regression analysis are summarized in Table 5. Age group, BMI categories, and elevated WC were strong predictors for the bias in selfreported height. Intake of fruits/vegetables $\geq 400 \mathrm{~g} / \mathrm{d}$ significantly contributed to the variance of difference between self-reported and measured height $(B=-0.01$, $P<0.05)$. Current daily smoking strongly predicted reduced bias in BMI based on self-reported height and weight $(B=0.02, P<0.05)$. There were no behavioral factors statistically predictive of the bias in self-reported weight or WC (both $P$ for $\mathrm{R}^{2}$ change of model 3 in selfreported weight and $\mathrm{WC}>0.05$ ). Age group, location, education, income, and BMI categories were found to be associated with the error in self-reported weight. Sex, age group, location, and elevated WC were associated with that of WC.

\section{Discussion}

This study is the first to evaluate the accuracy of selfreported height, weight, and WC among general adult Chinese, and it systematically examines the association between the bias in self-reported anthropometrics and demographic and behavioral factors. The analysis will potentially enrich the literature of accuracy of self-reported data as the Chinese traditionally believe that fatness is a

Table 3 The difference between self-reported and measured (SR-DM) height, weight, BMI, and WC by lifestyle factors in Jiangsu, China

\begin{tabular}{|c|c|c|c|c|c|c|c|c|c|c|c|c|c|}
\hline & & \multicolumn{3}{|c|}{ Height $(\mathrm{cm})$} & \multicolumn{3}{|c|}{ Weight (kg) } & \multicolumn{3}{|c|}{ BMI $\left(\mathrm{kg} / \mathrm{m}^{2}\right)$} & \multicolumn{3}{|c|}{$W C(\mathrm{~cm})$} \\
\hline & & $n$ & Mean & $95 \% \mathrm{Cl}$ & $n$ & Mean & $95 \% \mathrm{Cl}$ & $n$ & Mean & $95 \% \mathrm{Cl}$ & $n$ & Mean & $95 \% \mathrm{Cl}$ \\
\hline \multirow[t]{3}{*}{ Current daily smoking } & No & 3870 & 1.2 & $1.1,1.3$ & 4557 & -0.1 & $-0.3,0.0$ & 3709 & -0.5 & $-0.5,-0.4$ & 2613 & -1.7 & $-1.9,-1.5$ \\
\hline & Yes & 1167 & 1.0 & $0.8,1.1$ & 1310 & 0.1 & $-0.1,0.3$ & 1120 & -0.2 & $-0.3,-0.1$ & 656 & -0.7 & $-1.1,-0.2$ \\
\hline & $P$ value & \multicolumn{3}{|l|}{0.026} & \multicolumn{3}{|l|}{0.061} & \multicolumn{3}{|c|}{$<0.001$} & \multicolumn{3}{|c|}{$<0.001$} \\
\hline \multirow[t]{3}{*}{ Drinking alcohol within 30 days } & No & 3656 & 1.2 & $1.1,1.3$ & 4294 & -0.1 & $-0.2,0.1$ & 3502 & -0.4 & $-0.5,-0.3$ & 2471 & -1.6 & $-1.8,-1.4$ \\
\hline & Yes & 1381 & 1.1 & $0.9,1.2$ & 1573 & -0.1 & $-0.3,0.1$ & 1327 & -0.4 & $-0.5,-0.3$ & 798 & -1.1 & $-1.5,-0.7$ \\
\hline & $P$ value & 0.347 & & & 0.833 & & & 0.945 & & & 0.01 & & \\
\hline \multirow[t]{3}{*}{ Meat intake } & $<100 \mathrm{~g} / \mathrm{d}$ & 4248 & 1.2 & $1.1,1.2$ & 4997 & 0.0 & $-0.1,0.1$ & 4072 & -0.4 & $-0.4,-0.3$ & 2800 & -1.5 & $-1.7,-1.3$ \\
\hline & $\geq 100 \mathrm{~g} / \mathrm{d}$ & 715 & 1.0 & $0.7,1.2$ & 779 & -0.4 & $-0.6,-0.1$ & 687 & -0.5 & $-0.6,-0.3$ & 419 & -1.0 & $-1.5,-0.5$ \\
\hline & $P$ value & 0.188 & & & 0.033 & & & 0.228 & & & 0.048 & & \\
\hline \multirow[t]{3}{*}{ Fruits/vegetables intake } & $\geq 400 \mathrm{~g} / \mathrm{d}$ & 2774 & 1.3 & $1.2,1.4$ & 3050 & -0.1 & $-0.2,0.1$ & 2663 & -0.4 & $-0.5,-0.4$ & 1810 & -1.3 & $-1.6,-1.1$ \\
\hline & $<400 \mathrm{~g} / \mathrm{d}$ & 2235 & 0.9 & $0.8,1.1$ & 2786 & -0.1 & $-0.2,0.1$ & 2138 & -0.4 & $-0.4,-0.3$ & 1442 & -1.7 & $-2.0,-1.5$ \\
\hline & $P$ value & \multicolumn{3}{|c|}{$<0.001$} & \multicolumn{3}{|l|}{0.991} & \multicolumn{3}{|l|}{0.114} & \multicolumn{3}{|l|}{0.026} \\
\hline \multirow[t]{4}{*}{ Physical activity level } & Insufficient & 1008 & 0.9 & $0.6,1.1$ & 1110 & -0.1 & $-0.4,0.2$ & 967 & -0.4 & $-0.5,-0.3$ & 625 & -1.3 & $-1.7,-0.9$ \\
\hline & Moderate & 1392 & 1.0 & $0.9,1.2$ & 1548 & -0.2 & $-0.4,0.0$ & 1344 & -0.4 & $-0.5,-0.3$ & 883 & -1.4 & $-1.7,-1.1$ \\
\hline & Sufficient & 2637 & 1.3 & $1.2,1.4$ & 3209 & 0.0 & $-0.1,0.2$ & 2518 & -0.4 & $-0.5,-0.3$ & 1761 & -1.6 & $-1.9,-1.4$ \\
\hline & $P$ value & \multicolumn{3}{|c|}{$<0.001$} & \multicolumn{3}{|l|}{0.18} & \multicolumn{3}{|l|}{0.742} & \multicolumn{3}{|l|}{0.393} \\
\hline
\end{tabular}



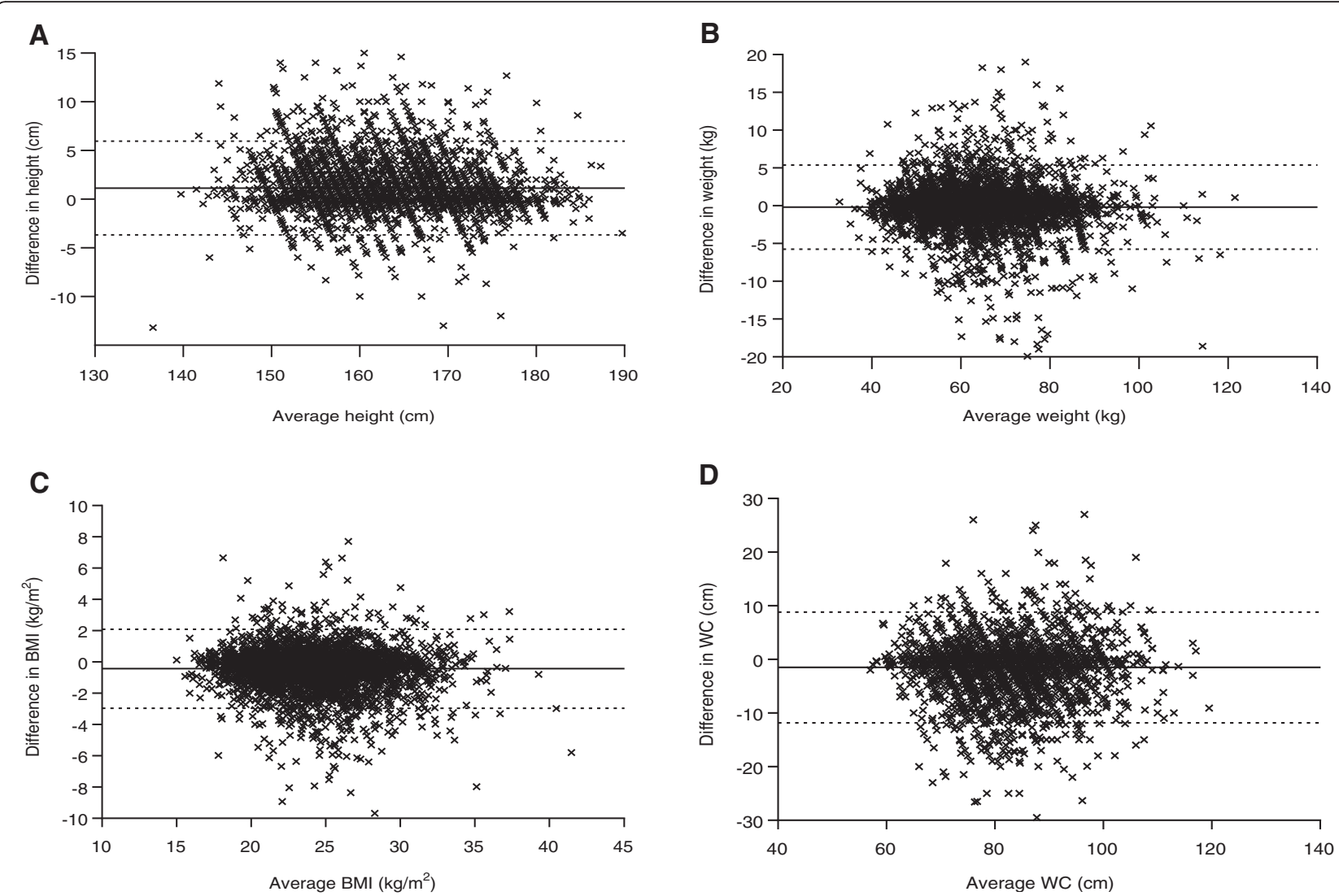

Fig. 2 Bland-Altman plots of the difference (self-reported minus measured) against the average ((self-reported + measured)/2) of height (a), weight (b), BMI (c) and WC (d). Solid line represents the mean difference and dotted line represents the $95 \%$ limits of agreement. BMl: body mass index; WC: waist circumference

symbol of abundance rather that a health problem [17], which is culturally different to the Western populations previously studied. Meanwhile, understanding the accuracy of self-reported anthropometrics in this population is important because the prevalence of obesity has increased considerably in the past two decades, and obesity has become one of the major public health problems [15-17].

Consistent with previous studies from other countries $[2,26]$, we found that self-reported and measured data of Chinese adults were highly correlated and had fairly good agreement with each other. However, self-reported height was overestimated whilst self-reported weight, BMI, and WC were all significantly underestimated, which was consistent with most existing studies $[5,8,13,14]$. Notably, the average difference between self-reported and measured height, weight, and BMI were lower than previously reported studies performed in Western countries $[2,5,6,10]$. This could be partly explained by the aforementioned social desirability among the Chinese that overweight or obesity is a sign of abundance rather than a health problem [17]. With the increased attention being given to overweight and obesity as major public health issues in recent years in China, people are undoubtedly becoming more sensitized to these issues. Therefore, it is possible that the self-reporting of anthropometric data in this study population could be more accurate than in previous studies.

Sex has been considered as one of the most important determinants for the accuracy of self-reported height, weight, and BMI, with more studies supporting that women were more likely to underestimate their BMI than men $[3,5,6,27]$. However, we have observed no significant difference in the bias of self-reported height, weight, or BMI between men and women in this study population. The relatively higher prevalence of overweight or obesity among men than women in China $(28.5 \%$ vs. $24.5 \%)[15,28]$ may be one of the main reasons for this, because overweight or obese people were proven to be more likely to have a greater extent of bias in self-reported data $[9,29,30]$. Another factor that may affect the sex difference in this study is the preferred units in which participants give their self-reported weight. While Chinese men tend to report weight in metric units $(\mathrm{kg})$, women are more likely to have reported weight in Chinese traditional units (Jin, where $1 \mathrm{Jin}=0.5 \mathrm{~kg}$ ), which may be subject to less rounding bias than if metric units were used [31]. 
Table 4 Errors in the classification of BMI categories and WC categories based on self-reported anthropometrics in Jiangsu, China (\%)

\begin{tabular}{|c|c|c|c|c|c|c|c|c|c|c|c|c|}
\hline \multirow[t]{2}{*}{ Categories } & \multicolumn{3}{|l|}{ SR } & \multicolumn{3}{|l|}{ DM } & \multicolumn{3}{|c|}{ Absolute Error } & \multicolumn{3}{|c|}{ Relative Error } \\
\hline & $\overline{M e n}$ & Women & All & Men & Women & All & Men & Women & All & $\overline{M e n}$ & Women & All \\
\hline \multicolumn{13}{|c|}{ BMI categories ( $\mathrm{kg} / \mathrm{m}^{2}$, according to the Chinese standard) } \\
\hline$<18.5$ & 2.9 & 3.7 & 3.3 & 2.3 & 2.4 & 2.3 & 0.6 & 1.3 & 1.0 & 27.0 & 56.1 & 42.6 \\
\hline $18.5-23.9$ & 45.9 & 51.4 & 48.8 & 43.5 & 43.3 & 43.4 & 2.4 & 8.1 & 5.4 & 5.6 & 18.7 & 12.5 \\
\hline $24.0-27.9$ & 38.6 & 34.6 & 36.5 & 40.0 & 38.3 & 39.1 & -1.4 & -3.7 & -2.6 & -3.5 & -9.7 & -6.5 \\
\hline$\geq 28.0$ & 12.5 & 10.3 & 11.4 & 14.2 & 16.0 & 15.2 & -1.6 & -5.7 & -3.9 & -11.6 & -35.8 & -25.5 \\
\hline \multicolumn{13}{|c|}{ WC categories (cm, according to the IDF standard for Chinese) } \\
\hline$<90$ of men/ <80 of women & 64.4 & 51.3 & 56.4 & 66.1 & 41.8 & 52.3 & -1.7 & 9.5 & 4.2 & -2.6 & 22.6 & 8.0 \\
\hline$\geq 90$ of men/ $\geq 80$ of women & 35.6 & 48.7 & 43.6 & 33.9 & 58.2 & 47.7 & 1.7 & -9.5 & -4.2 & 5.1 & -16.3 & -8.7 \\
\hline \multicolumn{13}{|c|}{ BMI categories ( $\mathrm{kg} / \mathrm{m}^{2}$, according to the WHO standard) } \\
\hline$<18.5$ & 3.0 & 5.2 & 4.0 & 2.5 & 4.7 & 3.6 & 0.5 & 0.4 & 0.4 & 20.5 & 9.5 & 11.6 \\
\hline $18.5-24.9$ & 61.6 & 69.9 & 65.5 & 57.3 & 60.4 & 58.8 & 4.3 & 9.5 & 6.7 & 7.6 & 15.7 & 11.4 \\
\hline $25.0-29.9$ & 29.4 & 21.3 & 25.6 & 33.7 & 29.1 & 31.4 & -4.3 & -7.8 & -5.8 & -12.7 & -26.8 & -18.5 \\
\hline$\geq 30.0$ & 6.0 & 3.7 & 4.9 & 6.6 & 5.8 & 6.2 & -0.6 & -2.1 & -1.3 & -9.0 & -36.7 & -21.0 \\
\hline \multicolumn{13}{|c|}{ WC categories (cm, according to the IDF standard for Americans) } \\
\hline$<102$ of men/ $<88$ of women & 95.7 & 82.4 & 88.6 & 95.2 & 79.3 & 87.2 & 0.4 & 3.1 & 1.4 & 0.5 & 3.9 & 1.6 \\
\hline$\geq 102$ of men/ $\geq 88$ of women & 4.3 & 17.6 & 11.4 & 4.8 & 20.7 & 12.8 & -0.4 & -3.1 & -1.4 & -9.2 & -15.0 & -10.6 \\
\hline
\end{tabular}

Abbreviations: BMI body mass index, WC waist circumference, SR self-reported, DM directly measured; Absolute error = SR-DM, Relative error $=$ Absolute error/ DM*100, WHO World Health Organization, IDF International Diabetes Federation

Although self-reported data were more accurate among Chinese adults compared to that of adults from Western countries, the proportion of respondents misclassified as non-obese using self-reported data was unexpectedly high (25.5\% for all). Dekkers et al. also observed a relative error of obesity prevalence based on self-reported height and weight that was over one-fifth (33.7\% of measured vs. $26.8 \%$ of self-reported) [2]. After changing the cut-off point standards of BMI categories and WC categories, the proportion of misclassification also changed. In other words, the reliability of estimating the prevalence of obesity according to self-reported measures not only depends

Table 5 Summary of hierarchical regression models for the difference between self-reported and measured height, weight, BMI, and WC in Jiangsu, China (B-value)

\begin{tabular}{|c|c|c|c|c|c|c|c|c|c|c|c|c|}
\hline & \multicolumn{3}{|l|}{ Height } & \multicolumn{3}{|l|}{ Weight } & \multicolumn{3}{|l|}{$\mathrm{BMI}$} & \multicolumn{3}{|l|}{ WC } \\
\hline & Model1 & Model2 & Model3 & Model1 & Model2 & Model3 & Model1 & Model2 & Model3 & Model1 & Model2 & Model3 \\
\hline Gender & 0.17 & $0.31^{*}$ & 0.18 & -0.02 & -0.04 & -0.01 & -0.08 & $-0.15^{*}$ & -0.10 & $-0.97^{*}$ & $-0.58^{*}$ & -0.30 \\
\hline Age group & $0.30^{*}$ & $0.31^{*}$ & $0.30^{*}$ & $0.14^{*}$ & $0.17^{*}$ & $0.15^{*}$ & $-0.05^{*}$ & -0.04 & $-0.04^{*}$ & $0.17^{*}$ & $0.33^{*}$ & $0.33^{*}$ \\
\hline Location & -0.09 & -0.05 & -0.05 & $0.42^{*}$ & $0.42^{*}$ & $0.44^{*}$ & $0.17^{*}$ & 0.13 & $0.14^{*}$ & $-0.81^{*}$ & $-0.74^{*}$ & $-0.70^{*}$ \\
\hline Education & -0.10 & -0.09 & -0.09 & -0.15 & $-0.23^{*}$ & $-0.22^{*}$ & -0.01 & -0.04 & -0.03 & 0.28 & 0.10 & 0.08 \\
\hline Household income level & -0.06 & -0.07 & -0.07 & $-0.20^{*}$ & $-0.19^{*}$ & $-0.19^{*}$ & -0.05 & -0.05 & -0.05 & 0.03 & 0.01 & 0.00 \\
\hline Measured BMI categories & & $0.53^{*}$ & $0.51^{*}$ & & $-0.83^{*}$ & $-0.83^{*}$ & & $-0.56^{*}$ & $-0.56^{*}$ & & -0.18 & -0.17 \\
\hline Elevated WC & & $-0.01^{*}$ & $-0.01^{*}$ & & 0.00 & 0.00 & & 0.00 & 0.00 & & $-0.02^{*}$ & $-0.02^{*}$ \\
\hline Current daily smoking & & & 0.00 & & & 0.00 & & & $0.02^{*}$ & & & 0.00 \\
\hline Drinking alcohol within 30 days & & & 0.00 & & & 0.00 & & & 0.00 & & & 0.00 \\
\hline Meat intake $\geq 100 \mathrm{~g} / \mathrm{d}$ & & & 0.00 & & & 0.00 & & & 0.00 & & & 0.00 \\
\hline Fruits/vegetables intake $<400 \mathrm{~g} / \mathrm{d}$ & & & $-0.01^{*}$ & & & 0.00 & & & 0.00 & & & 0.00 \\
\hline Physical activity level & & & 0.11 & & & 0.04 & & & 0.04 & & & -0.03 \\
\hline$R^{2}$ & 0.022 & 0.033 & 0.036 & 0.007 & 0.028 & 0.029 & 0.004 & 0.045 & 0.048 & 0.016 & 0.071 & 0.073 \\
\hline$F$ for $R^{2}$ Change & $22.418^{*}$ & $26.926^{*}$ & $3.748^{*}$ & $8.472^{*}$ & $61.921^{*}$ & 1.279 & $3.817^{*}$ & $101.945^{*}$ & $3.272^{*}$ & $10.428^{*}$ & $95.341^{*}$ & 1.185 \\
\hline
\end{tabular}

Abbreviations: $B M I$ body mass index, WC waist circumference 
on the absolute accuracy of self-reported data, but also depends on the BMI and WC distribution, as well as the cut-off point standard of obesity (overall or abdominal) in a certain population. The Bland-Altman plots demonstrated that participants with average BMI values close to the cut-off points of overweight or with average WC values close to the cut-off point of elevated WC had much greater variance of bias. This might be the reason for the high obesity misclassification rate in this research population.

Although considerable skepticism has been expressed by researchers about the accuracy and the validity of selfreported data $[2,6]$, for reasons of cost and practicality, they are still often used in surveillance and routine clinical assessment of obesity to calculate BMI $[6,9,14]$. To minimize biases resulting from self-reported estimates, some researchers have attempted to identify correction factors or formulas that could be applied to help minimize such bias $[6,11]$. Our finding makes the feasibility of such adjustment further complicated. Researchers should be cautious of the possibility that such adjustment might lead to greater biases in estimates of BMI-related morbidity and mortality risk because, on the one hand, the BMI distribution of a population is dynamic rather than fixed, and on the other hand, even if the correcting coefficients were established for a population, it could be inappropriate to apply this to other populations due to their difference in the cut-off point standard of obesity. Meanwhile, it should not be forgotten that the proportion of misclassification of BMI categories based on self-reported data was rather high. Overall, based on the findings of this analysis as well as the results of previous studies $[2,3,6]$, the self-reported anthropometric data could be biased and misleading.

The bias of self-reported WC in this study (underestimated by $-1.5 \mathrm{~cm}$ ) was in the middle of the range compared to previous studies $[2,10]$. The misclassification rate of abdominal obesity was relatively lower than that of overall obesity (both underreported, $8.7 \%$ vs. $25.5 \%$ ). Nonetheless, this does not mean that self-reported WC is better than BMI calculated from self-reported height and weight in predicting obesity, for there was much greater discrepancy and bigger fluctuation in the selfreported WC data than in BMI based on self-reported height and weight.

We observed that participants with socially perceived "healthy lifestyles," such as not smoking or not drinking alcohol, eating less meat, consuming more fruits/vegetables, and being physically active, were more likely to overreport their height but underreport their WC. Smoking was found to be associated with more accurate BMI based on self-reported height and weight, which concurs with the findings of former studies [2, 12]. More intake of fruits/vegetables was further found to be significantly associated with greater extent of bias in self-reported height by multifactorial analysis in this study. It appears that Chinese adults with behaviors which are "aligning with social desirability" are more likely to overestimate their height and underestimate their weight and WC. Some researchers have argued that the pressures of social desirability in a face-to-face interview, as performed in the present study, may have resulted in greater bias in selfreported measures [5,9], which could partly explain our findings on the association of certain behaviors and the accuracy of self-reported data.

By randomly sampling from a general community population, strictly adhering to a standard protocol of anthropometric measurements, relatively large sample size, together with no time lapse between self-reporting and measuring, this study provides rather reliable evidence in the accuracy of self-reported data and its determinants as well. However, we should keep in mind that the disadvantaged residents in the research population, such as the elderly, those living in rural areas, and those with low education or low income, have relatively higher unawareness rate of their anthropometrics, limiting our confidence in the findings. Moreover, it should not be forgotten that respondents of this survey did know in advance that their height, weight, and WC would be measured, possibly resulting in a bias towards more accurate reporting.

\section{Conclusions}

In a general adult Chinese population, height was overreported whilst weight, BMI, and WC were underreported, and such bias could be affected by a multitude of factors, including demographic characteristics (including sex, age, location, and education), weight status, and behavioral factors like smoking and fruit/vegetable intake. Moreover, the obesity misclassification rate based on self-reported measures was high in the general population, and such rates were associated with the distribution of anthropometrics and the cut-off point standard of obesity, which could be different from population to population. Given the above findings, we suggest for future studies that: if anthropometric measurements are not key study variables, rather than relying on self-reported data, they should be excluded to reduce the cost of data collection and to prevent deducing an inaccurate estimation, and if anthropometric measurements are crucial variables, they should be directly measured. Though no measurement procedure is without error, we think that such error for direct measurements could be better controlled in analysis.

\section{Abbreviations \\ $\mathrm{BMI}$, body mass index; Cl, confidence interval; DM, directly measured; DSP, disease surveillance point; SR, self-reported; WC, waist circumference}

\section{Acknowledgements}

This study was funded by the Jiangsu Provincial Commission of Health and Family Planning (Jiangsu Preventive Medicine Grant, Y2013052). 


\section{Authors' contributions}

SL conceived the study, participated in its design and coordination, performed the statistical analysis, and drafted the manuscript. MW participated in the design of the study and writing of the manuscript. SJ, QX and JZ contributed to the study design. All authors read and approved the final manuscript.

\section{Competing interests}

The authors declare that they have no competing interests.

Received: 7 January 2016 Accepted: 23 June 2016

Published online: 11 August 2016

\section{References}

1. Bolton-Smith C, Woodward M, Tunstall-Pedoe H, Morrison C. Accuracy of the estimated prevalence of obesity from self reported height and weight in an adult Scottish population. J Epidemiol Community Health. 2000;54:143-8.

2. Dekkers JC, van Wier MF, Hendriksen IJ, Twisk JW, van Mechelen W. Accuracy of self-reported body weight, height and waist circumference in a Dutch overweight working population. BMC Med Res Methodol. 2008;8:69.

3. Sherry B, Jefferds ME, Grummer-Strawn LM. Accuracy of adolescent selfreport of height and weight in assessing overweight status: a literature review. Arch Pediatr Adolesc Med. 2007;161:1154-61.

4. Ezzati M, Martin H, Skjold S, Vander Hoorn S, Murray CJ. Trends in national and state-level obesity in the USA after correction for self-report bias: analysis of health surveys. J R Soc Med. 2006:99:250-7.

5. Pursey K, Burrows TL, Stanwell P, Collins CE. How accurate is web-based self-reported height, weight, and body mass index in young adults? J Med Internet Res. 2014;16:e4.

6. Connor Gorber S, Tremblay M, Moher D, Gorber B. A comparison of direct vs. self-report measures for assessing height, weight and body mass index: a systematic review. Obes Rev. 2007:8:307-26.

7. Hattori A, Sturm R. The obesity epidemic and changes in self-report biases in BMI. Obesity (Silver Spring). 2013;21:856-60.

8. Bigaard J, Spanggaard I, Thomsen BL, Overvad K, Tjonneland A. Selfreported and technician-measured waist circumferences differ in middleaged men and women. J Nutr. 2005;135:2263-70.

9. Stommel M, Osier N. Temporal changes in bias of body mass index scores based on self-reported height and weight. Int J Obes (Lond). 2013;37:461-7.

10. Cullum A, McCarthy A, Gunnell D, Davey Smith G, Sterne JA, Ben-Shlomo Y. Dietary restraint and the mis-reporting of anthropometric measures by middle-aged adults. Int J Obes Relat Metab Disord. 2004;28:426-33.

11. Stommel M, Schoenborn CA. Accuracy and usefulness of BMI measures based on self-reported weight and height: findings from the NHANES \& NHIS 2001-2006. BMC Public Health. 2009;9:421.

12. Bolton-Smith C, Woodward M, Tunstall-Pedoe H, Morrison C. Accuracy of the estimated prevalence of obesity from self reported height and weight in an adult. Scottish population. J Epidemiol Community Health. 2000;54: 143-8.

13. Krul AJ, Daanen HA, Choi H. Self-reported and measured weight, height and body mass index (BMI) in Italy, the Netherlands and North America. Eur J Public Health. 2011:21:414-9.

14. Spencer EA, Appleby PN, Davey GK, Key TJ. Validity of self-reported height and weight in 4808 EPIC-Oxford participants. Public Health Nutr. 2002;5: 561-5.

15. Li X, Jiang Y, Hu N, Li Y, Zhang M, Huang Z, Zhao W. Prevalence and characteristic of overweight and obesity among adults in China, 2010 (in Chinese). Chin J Prev Med. 2012;46:683-6.

16. Chen CM. Overview of obesity in Mainland China. Obes Rev. 2008;9 Suppl 1: 14-21.

17. Wang $H$, Zhai F. Programme and policy options for preventing obesity in China. Obes Rev. 2013;14 Suppl 2:134-40.

18. Yu Q, Zhou J, Yang J, Tao R, Wang P, Han R, Wu M. Evaluation on the representativeness and data quality of sample of death survey in Jiangsu Province of China (in Chinese). Jiangsu Prev Med. 2010;21:56-8.

19. Villanueva EV. The validity of self-reported weight in US adults: a population based cross-sectional study. BMC Public Health. 2001:1:11.

20. Kish L, Verma V. Complete censuses and samples. J Off Stat. 1986;2:381-95.
21. Harris HR, Bergkvist L, Wolk A. An estrogen-associated dietary pattern and breast cancer risk in the Swedish Mammography Cohort. Int J Cancer. 2015; 137:2149-54.

22. Lyu S, Su J, Xiang Q, Wu M. Association of dietary pattern and physical activity level with triglyceride to high-density lipoprotein cholesterol ratio among adults in Jiangsu, China: a cross-sectional study with sex-specific differences. Nutr Res. 2014;34:674-81.

23. China WGoOi. Chinese guideline for the control and prevention of overweight and obesity in adults (excerpt) (in Chinese). Acta Nutrimenta Sinica. 2004;26:4

24. Alberti KG, Zimmet P, Shaw J, Group IDFETFC. The metabolic syndrome-a new worldwide definition. Lancet. 2005:366:1059-62.

25. Bland JM, Altman DG. Statistical methods for assessing agreement between two methods of clinical measurement. Lancet. 1986:1:307-10.

26. Cullum A, McCarthy A, Gunnell D, Smith GD, Sterne J, Ben-Shlomo Y. Dietary restraint and the mis-reporting of anthropometric measures by middle-aged adults. Int J Obes. 2004;28:8.

27. Hayes AJ, Clarke PM, Lung TW. Change in bias in self-reported body mass index in Australia between 1995 and 2008 and the evaluation of correction equations. Popul Health Metr. 2011;9:53.

28. Xi B, Liang $Y$, He T, Reilly KH, Hu Y, Wang Q, Yan Y, Mi J. Secular trends in the prevalence of general and abdominal obesity among Chinese adults, 1993-2009. Obes Rev. 2012:13:287-96.

29. Connor Gorber S, Tremblay MS. The bias in self-reported obesity from 1976 to 2005: a Canada-US comparison. Obesity (Silver Spring). 2010;18:354-61.

30. Hayes AJ, Kortt MA, Clarke PM, Brandrup JD. Estimating equations to correct self-reported height and weight: implications for prevalence of overweight and obesity in Australia. Aust N Z J Public Health. 2008;32:542-5.

31. Bopp M, Faeh D. End-digits preference for self-reported height depends on language. BMC Public Health. 2008;8:342.

\section{Submit your next manuscript to BioMed Central and we will help you at every step:}

- We accept pre-submission inquiries

- Our selector tool helps you to find the most relevant journal

- We provide round the clock customer support

- Convenient online submission

- Thorough peer review

- Inclusion in PubMed and all major indexing services

- Maximum visibility for your research

Submit your manuscript at www.biomedcentral.com/submit 